\title{
Monsoon Impact on El Niño in the Early Holocene
}

El Niño/Southern Oscillation is the most dramatic example of interannual climate variability in our world today (Philander, 1990). Recent paleoclimate evidence, however, seems to suggest that strong El Niño/Southern Oscillation events developed only after about $6000-7000$ yrs BP (years before present). Time series of clastic deposits in an Andean lake in Ecuador (Rodbell et al., 1999) and archaeological deposits in northern Peru (Sandweiss et al., 1996) indicate less severe flooding events along the west coast of tropical South America before the mid-Holocene; records of fires in Australia (McGlone et al., 1992) and isotopic records from fossil coral in the western tropical Pacific (Gagan et al., 1998) also indicate less variable monsoon rainfall in the mid- and early Holocene. Here, a coupled oceanatmosphere model is used to investigate El Niño variability in the early Holocene. Our preliminary study suggests that El Niño intensity in the early Holocene is reduced at least in part by the remote influence of the intensified Asian monsoon on the Pacific trades.

The model is a fully coupled oceanatmosphere model - the Fast Ocean-Atmosphere Model (FOAM) (Jacob, 1997), in which an R15 AGCM is coupled with a $2.8^{\circ}$ longitude $/ 1.4^{\circ}$ latitude resolution OGCM. The model physics are similar to those of the NCAR CSM. A modern control run is performed under present climate forcing for 650 years without flux correction, and reproduces the present climatology and climate variability in the tropics adequately, as does the NCAR CSM (Meehl and Arblaster, 1998; OttoBliesner, 1999). In particular, tropical climate variability is dominated by an El Niño mode, which has the maximum SST variability in the eastern equatorial $\mathrm{Pa}$ cific (Figure 1a), and which has the power spectrum peaking in the period band of 2.5-7 years (Figure $1 \mathrm{~b}$ ). Similar to the CSM, however, the strength of El Niño is about $60 \%$ of that in observations.

Climate variability in the early Holocene is simulated in a sensitivity experiment that is forced by the insolation of 11,000 yrs BP (Berger, 1978). This Holocene experiment starts from the $300^{\text {th }}$ year of the modern simulation. The model is then integrated for 100 years with the last 50 years used for comparison with the modern simulation of the
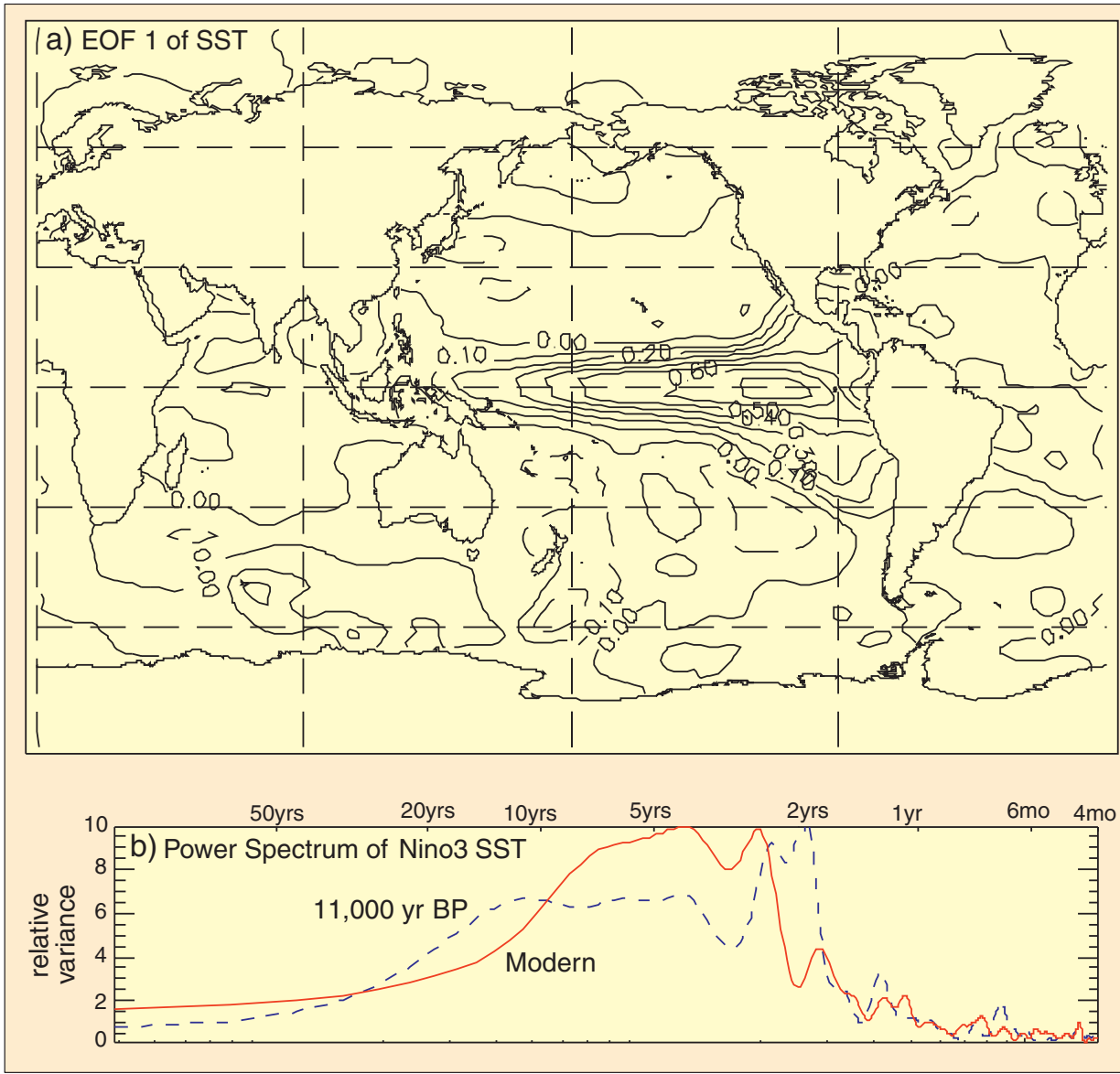

Figure 1: (a) The pattern of the first empirical orthogonal function (EOF) of SST for the modern simulation, which shows the spatial pattern of the El Niño mode (contour interval arbitrary). The time series of the EOF coefficient (not shown) resembles closely that of the SST in the Niño 3 region $\left(140^{\circ} \mathrm{W}\right.$ to $90^{\circ} \mathrm{W}, 5^{\circ} \mathrm{S}$ to $5^{\circ} \mathrm{N}$ ). (b) The power spectrum (units arbitrary) of the Niño 3 SST for the modern (red) and 11,000 yr BP (blue) simulations.

same years. One striking feature in the Holocene simulation is a substantial reduction in the magnitude of El Niño, by about $20 \%$ compared with the modern control as seen in the SST power spectrum (Figure 1b). The reduction of variability associated with El Niño seems to agree with the paleoclimate evidence discussed above (Rodbell et al., 1999; Sandweiss et al., 1996; McGlone et al., 1992; Gagan et al., 1998).

The Holocene El Niño appears to be, at least in part, suppressed by the intensified Asian monsoon. In the early Holocene, the earth is closest to the sun in June, and therefore the seasonal cycle of the solar radiation is enhanced by about $10 \%$ in the northern hemisphere relative to the present. One of the most important tropical climate responses to this increase of the insolation cycle is a significantly intensified Asian summer monsoon (Kutzbach and Otto-Bliesner, 1982). This enhanced Asian monsoon can further induce wind changes in the remote equatorial Pacific through the atmospheric Walker circulation. During boreal summer, the enhanced Indian monsoon strengthens the deep convection in the eastern Indian Ocean-western Pacific warm pool, which increases the easterly trades, and in turn the upwelling and cooling in the central to eastern Pacific (Shukla, 1987; Barnett et al., 1989). The colder eastern Pacific SST further strengthens the trades through the Bjerknes feedback mechanism (Bjerknes, 1969). The combination of Asian monsoon forcing and positive ocean-atmosphere feedback leads to an increase in the equatorial trades of $1 \mathrm{~m} / \mathrm{s}$ (Figure 2a), and an associated SST cooling of $0.5^{\circ} \mathrm{C}$ (Figure $2 \mathrm{~b}$ ) over the central to eastern Pacific $\left(160^{\circ} \mathrm{E}\right.$ to $\left.90^{\circ} \mathrm{W}\right)$, which amount to about 10 to $20 \%$ of the total wind and SST seasonal anomalies, respectively. Since most El Niño warm events start in northern hemisphere 


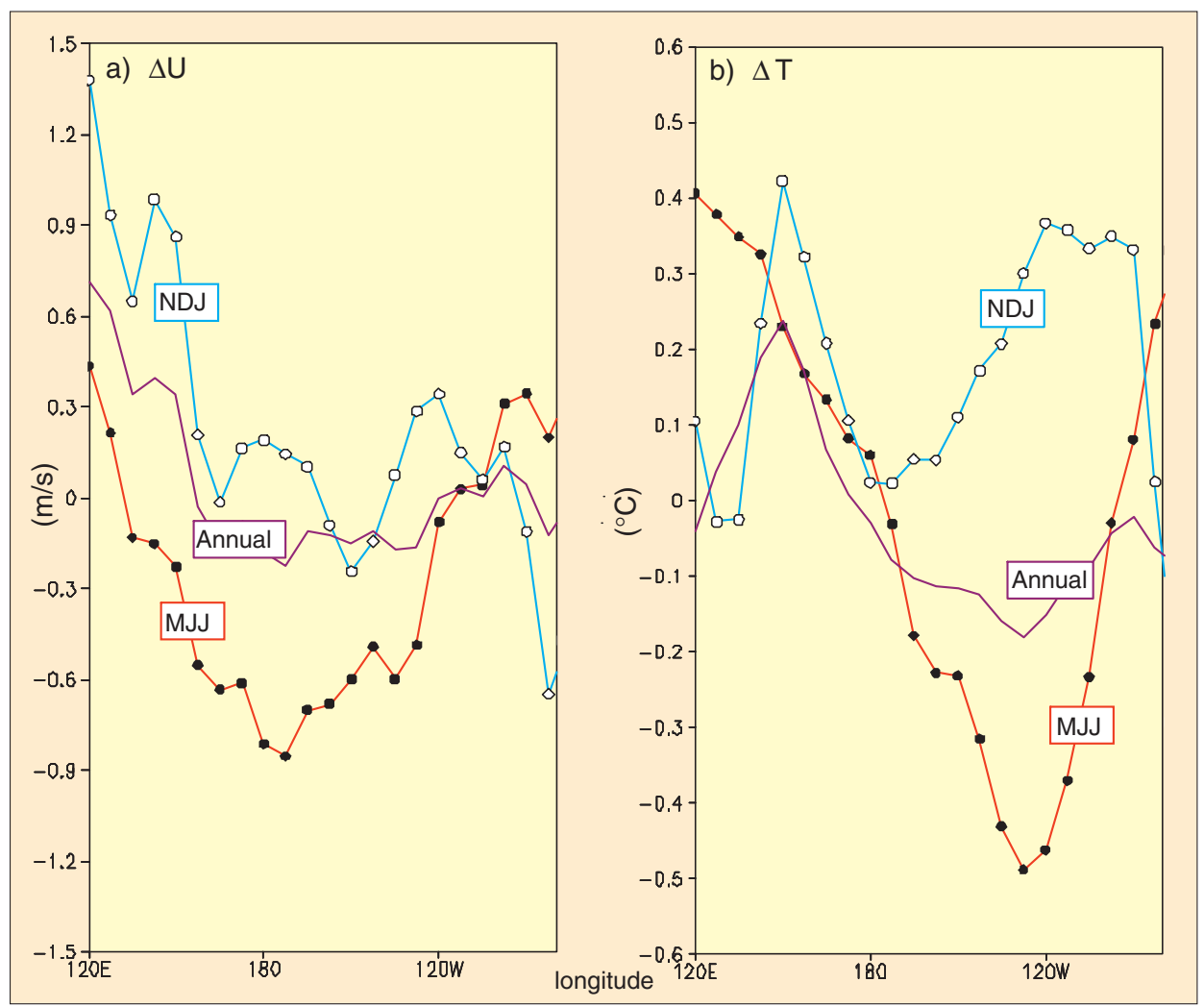

spring and peak in the following winter, this increase of the trades and upwelling induced cooling in the early Holocene tends to suppress the growth of warm El Niño events in summer and therefore reduces their final amplitude later in the year (Barnett et al., 1989; Webster and Yang, 1992).

The reduction of El Niño variability could also be related to the enhanced annual mean trades and enhanced annual upwelling cooling of the central to eastern Pacific (Barnett et al., 1989; Masumoto and Yamagata, 1991). In the Holocene run, the annual mean trades are stronger by $0.2 \mathrm{~m} / \mathrm{s}$ (Figure 2a) and the SST is cooled by $0.2^{\circ} \mathrm{C}$ (Figure $2 \mathrm{~b}$ ) in the central to eastern Pacific. A colder annual mean in the eastern Pacific has also been produced in two other coupled model experiments in the early to midHolocene (Bush, 1999; Clement et al., 1999) and, as pointed out by Clement et al. (1999), may not be inconsistent with the presence of certain mollusk fauna along the coast of South America in the mid-Holocene (Sandweiss et al., 1996). This lower annual mean SST could be related to two processes. First, the Asian summer monsoon enhancement, because of its nonlinear augmentation of latent heat release in the warm season, dominates over the winter monsoon enhancement, as indicated by the weaker and
Figure 2: The change (11,000 yr BP minus modern) of (a) surface zonal (u-component) wind $(\mathrm{m} / \mathrm{s})$ and $(\mathrm{b})$ surface air temperature $\left({ }^{\circ} \mathrm{C}\right)$ averaged within $5^{\circ}$ of the equator in the Pacific sector. The summer (May, June and July average), winter (November, December and January), and annual mean are plotted in red, blue and purple, respectively. The negative values of wind anomaly in the central Pacific implies stronger wind blowing from east to west, i.e, an enhancement of the climatological easterlies. The surface air temperature resembles closely the SST over the tropical ocean.

References for this article can be found at http://www.pages.unibe.ch/publications/ newsletters/ref992.html

\section{WORKSHOP}

\section{ANNOUNCEMENT}

\section{images \\ Russian \\ IMAGES Workshop}

opposite sign of trade response in winter (Figure 2a), and therefore results in stronger annual mean easterlies in the remote atmospheric response over the Pacific. Second, the anomalous upwelling in summer forces a shallower thermocline in the eastern Pacific, which enables the upwelling to affect SST more efficiently in summer than occurs in winter when the thermocline is anomalously deep. While this note emphasizes the importance of the remote monsoon forcing, it is also likely that local processes within the Pacific sector also contribute to changes in the behavior of El Niño in the Holocene (Clement et al., 1999).

\section{ACKNOWLEDGement}

We appreciate a helpful discussion with Dr. M. Cane.

\section{Z. LiU, R. Jacob, J. Kutzbach}

Center for Climatic Research and Department of

Atmospheric and Oceanic Sciences

University of Wisconsin - Madison, USA

zn|@ocean.meteor.wisc.edu

\section{S. HARRISON}

Max-Planck Institute of Biogeochemistry Jena, Germany

sandy.harrison@bgc-jena.mpg.de

\section{J. Anderson \\ Department of Atmospheric and Oceanic Sciences University of Wisconsin - Madison, USA}

\section{Moscow, Russia,2-6 November, 1999}

This meeting is aimed at developing highresolution paleoceanography in Russia and coordination of the work between different institutions nationally and internationally.

Our goals are:

1. Review of existing materials applicable to the high-resolution post-glacial paleoceanography from Eurasian Arctic and Far-Eastern seas.

2. Inter-regional correlation of sedimentary records to reveal paleoceanoduring deglaciation and Holocene.

3. Coordination of research methods and theoretical approaches developed in different institutions.

4. Planning of future cooperation including joint expeditions, exchange of data and samples, development of a collective database, and encouragement of cooperative analytical work. A more detailed workshop announcement can be found on the PAGES website calendar page.

\section{Elena Ivanova, Michael Levitan}

Shirshov Institute of Oceanology,

Russian Academy of Sciences, Moscow, Russia

eivanova@geo.sio.rssi.ru

mlevitan@sedim.msk.ru graphic and paleoclimatic changes 